ojs.uv.es/index.php/qdfed

Rebut: 30.04.2021. Acceptat: 10.09.21

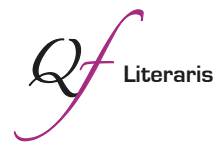

Per a citar aquest article: Sánchez Zapatero, Javier. 202I. "Víctimas y victimarios en la literatura española de la memoria, de la Guerra Civil a la actualidad: el caso de Dicen, de Susana Sánchez Arins”.

Quaderns de Filologia: Estudis Literaris XXVI: 2I-37.

doi: $10.7203 /$ qdfed.26.22096

\title{
Víctimas y victimarios en la literatura española de la memoria, de la Guerra Civil a la actualidad: el caso de Dicen, de Susana Sánchez Arins
}

Victims and perpetrators in Spanish Memory Literature, from the Spanish Civil War to the present: the case of Dicen, by Susana Sánchez Arins

JaVier SÁNChez Zapatero Universidad de Salamanca zapa@usal.es

Resumen: El artículo muestra cómo, desde la propia Guerra Civil, diversos autores concibieron su literatura como una forma de reivindicar el legado de las víctimas de la violencia totalitaria. Partiendo de esta premisa, se reflexiona, en primer lugar, sobre cómo la reiteración de procedimientos centrados en recuperación de las voces de los represaliados ha tenido como consecuencia indirecta la difuminación de la figura del perpetrador en la literatura española de los siglos xx y xxi; y, en segundo lugar, sobre las características de obras que, como Dicen, de Susana Sánchez Arins, intentan subvertir este panorama.

Palabras clave: víctima; victimario; literatura de la memoria; Arturo Barea; Susana Sánchez Arins.

Abstract: The article exposes how, since the Spanish Civil War, some authors conceived their literature as a way of vindicating the legacy of the victims of totalitarian violence. Starting from this premise, it is reflected, in the first place, how the reiteration of procedures focused on recovering the voices of the reprisals has had as an indirect consequence the blurring of the figure of the perpetrator in Spanish Literature. Secondly, the paper reflects on the characteristics of novels such as Dicen, by Susana Sánchez Arins, which try to subvert this panorama. Keywords: victim; perpetrator; memory literature; Arturo Barea; Susana Sánchez Arins.

\section{1. "Los asesinos no tienen nombre"}

En I938, en plena Guerra Civil, vio la luz la compilación de relatos de Arturo Barea Valor y miedo. Enmarcadas casi en su totalidad en el Madrid republicano de la resistencia y dotadas de un evidente valor propagandístico, las narracio- 
nes recogidas en el volumen trataban de mostrar la dimensión intrahistórica de la contienda al otorgar su protagonismo a las víctimas del hambre, el miedo y la violencia que esta trajo consigo. En ellas, de hecho, es habitual la presencia como personajes de combatientes anónimos o de miembros de las clases populares que sufrieron en sus propias carnes las consecuencias de los bombardeos franquistas y la durísima situación a la que el asedio y las carencias condenaron a la capital.

Así se observa, por ejemplo, en "Proeza”, que, con un ánimo más descriptivo que estrictamente narrativo, muestra los terribles efectos de un ataque aéreo en Vallecas -todavía pueblo independiente de Madrid por aquel entonces-, uno de los lugares más castigados por la aviación rebelde debido a su condición obrera y su cercanía con algunos frentes de combate. De forma muy breve, y en consonancia con el carácter aséptico y conciso que caracteriza a toda la literatura de Barea, el relato comienza describiendo cómo la guerra ha cambiado el paisaje humano de la localidad, en la que "ya no hay hombres" porque "unos se fueron al frente, otros al trabajo en Madrid" y solo quedan "mujeres [que] toman el sol sentadas en sillas bajas de paja" y "un enjambre de chiquillos que juegan sobre la tierra dura" (20I9: I66). Después, se relata cómo la llegada de una cuadrilla de bombarderos de la flota rebelde irrumpe para vaciar sus cargas, rompiendo así con la placidez de la escena inicial de aire costumbrista con la que el autor parecía querer mostrar la inocencia y la condición de población civil, ajena a las lógicas de combate, de las mujeres y los niños que, finalmente, terminaron "proyectados (...) en todas direcciones", provocando que en la explanada quedaran "veintitrés cadáveres y tres heridos" (20I9: I67). Con tremenda explicitud, Barea detalla las dramáticas consecuencias de las explosiones, centrándose en lo sucedido a una de las familias afectadas, cuya casa quedó reducida a ruinas:

La mujer cayó muerta en la puerta de su casa. Los trozos de carne del niño estaban mezclados con los trozos de carne de la madre. La hija mayor -dieciséis años- cayó muerta sobre el cadáver de su hermana de doce. Uno de los niños, de seis años, quedó tendido en el suelo, vivo, falto de un pie y la espalda abierta. Otro de diez años, ileso, pero echando sangre por sus orejas, reventados sus oídos por las explosiones, salió corriendo, llevando a través del campo el cuerpo de la hermanita menor de cuatro años. Lo llevó él mismo hasta la casa de socorro: había recibido el polvo de la metralla y tenía más de cien heridas diminutas en su cuerpecito (2019: 167). 
Para dotar de veracidad a lo narrado, el relato ubica lo sucedido en unas coordenadas temporales y especiales muy concretas -"el 20 de enero de I937, aproximadamente a las once de la mañana (...) [en] la calle de Carlos Orioles en Vallecas" (2019: I66-I67)- e incluye en su parte final al propio Barea como personaje, que confiesa en su condición de narrador homodiegético que el padre, ausente en momento del bombardeo por encontrarse trabajando, es quien le "ha contado la historia" (2019: I67). Tras semejante confesión, de indudable valor pragmático en la medida que expone la barbarie de los franquistas y subraya la autenticidad del relato -también reforzada por su posterior inclusión en La llama (I944), tercera parte de la trilogía autobiográfica del autor-, la narración se cierra abruptamente indicando de forma explícita los nombres del padre y de la madre: "El padre se llama: Raimundo Malanda Ruiz. La madre se llamaba: Librada García Pozo” (2019: I67).

Al incluir esta información, Barea confirma cómo, en ocasiones, la literatura puede servir para "prestar voz y palabras a quienes no las tuvieron" (López de la Vieja, 2003: 135), de manera que adquiere una dimensión memorística que, en este caso concreto, permite nombrar, y con ello hacer presente, a quien ha sido aniquilado y a quien se quiere excluir de la historia. No en vano, es evidente que, trascendiendo la estricta correspondencia de lo sucedido con la realidad y de los nombres aportados por el autor con personas que efectivamente existieron -que, en el fondo, resulta insustancial, puesto que, gracias al poder evocador de la ficción, aunque los acontecimientos concretos que aparecen en el relato no hubieran ocurrido, sí lo hicieron otros análogos que pueden verse representados en él-, "Proeza" es una paradigmática muestra de cómo la literatura puede servir, además de para recordar, para "hacer recordar", en la medida en la que gracias a su existencia es posible que quede constancia de la identidad de quien, si no fuera por la coda final en la que se especifican los nombres, no habría rastro más allá del recuerdo íntimo y familiar.

Ahora bien, resulta curioso que, tras desvelar la identidad de las víctimas, Barea culmine el relato con dos frases que, a modo de sentencia, terminan concluyendo que "el avión era un trimotor junker alemán" y "los asesinos no tienen nombre” (20I9: I67). Si la primera sirve para dejar bien claro de quién es la responsabilidad del ataque y sobre qué conciencias ha de caer la condena moral de la tragedia, denunciando con ello la brutalidad con la que se hostigó a la población civil durante el conflicto bélico, la segunda resulta tremendamente significativa por su pretensión de obviar cualquier referencia hacia los culpables. Para el autor, importan las atrocidades e importan quienes las 
sufren, pero no tanto quienes las cometen, lo que se pone de manifiesto de forma sistemática en los cuentos Valor y miedo, en los que el enemigo aparece representado como una masa uniformada de destrucción, casi como una maquinaría en la que no se detectan rasgos humanos. La omisión de referencias concretas a los rebeldes entronca con la intención de la compilación de relatos de, por un lado, ceder el primer plano de la narración al colectivo intrahistórico que vio truncados sus proyectos vitales por culpa de la guerra y, por otro, denigrar a quienes, para Barea, no merecían siquiera ser nombrados por la absoluta falta de humanidad con la que se comportaron, como si se tratase de simples bestias concebidas para maltratar a los demás.

\section{2. "Recuérdalo tú y recuérdalo a los otros"}

Los asesinos no tienen nombre porque ni siquiera eso merecen tener, parece decir el autor con la última frase del relato, en la que anticipa una característica que, con el paso del tiempo, se ha ido revelando fundamental para entender la evolución de la literatura sobre el conflicto bélico y sus consecuencias, y de forma especial la que se escribió desde el exilio y la que durante los últimos años se ha ido convirtiendo en tendencia recurrente en el campo literario español. Y es que, como ha señalado Lauge Hansen, "el discurso predominante de la cultura de la memoria del Estado español fijó desde el principio su punto de vista en el sufrimiento de la víctima" (2018).

Semejante característica, que entronca con la postura de Walter Benjamin (2008) de reivindicar el punto de vista del oprimido, puede ser explicada atendiendo a dos razones. En primer lugar, es innegable que desde las últimas décadas del siglo xx toda la cultura de la memoria ha estado marcada, a nivel universal, por la creciente relevancia que han ido adquiriendo tanto los discursos como la representación de los testigos, sometidos a un proceso de legitimación que, en un contexto marcado por el cuestionamiento de los grandes relatos totalizadores, llevó a Annette Wieviorka a referirse a la emergencia de la "era del testigo" (2006). Los testimonios no solo interesan por su valor cognitivo, y por la capacidad que en consecuencia adquieren para reconstruir y transmitir información sobre un acontecimiento histórico, sino también y sobre todo por su dimensión humana, lo que adquiere una gran importancia en el caso de las víctimas. Es decir, en episodios traumáticos y violentos como el que, por ejemplo, narra Barea en "Proeza", importa saber que quien cuenta la historia posee la autoridad que le da el haberla conocido de primera mano 
y puede dotar a su discurso del componente emocional que le da el haber sufrido de primera mano sus consecuencias. De ese modo, como ha señalado Ricard Vinyes, "el sujeto-víctima constituye un lugar de encuentro con el que [se] (...) genera el espacio de consenso moral sustentado en el sufrimiento impuesto" (2010).

La segunda razón que se ha de tener en cuenta a la hora de analizar la preponderancia casi exclusiva del discurso de los derrotados está relacionada con las propias particularidades de la historia nacional, que han provocado una situación en la que para las víctimas, sometidas a un sistemático proceso de exclusión de la esfera pública, ofrecer la versión de lo sucedido sea, más que una alternativa, una necesidad y una obligación. Como señaló Todorov, en aquellas situaciones en las que los verdugos se arrogaron "el derecho de controlar la selección de elementos que deben ser conservados", recordar se convierte "en un deber: el de acordarse, el de testimoniar" (2000: I6-I8). Este imperativo ha estado presente en la cultura española desde la propia Guerra Civil, como demuestra el caso del propio Barea o como demuestran casos sintomáticos del exilio como los de Max Aub, María Teresa León o Luis Cernuda, que evidencian cómo el colectivo republicano fue configurando su relato y su interpretación de la guerra a través de un discurso férreamente asentado sobre la necesidad imperiosa de recordar, entendida casi como una tarea vital. El reconocimiento del primero de haber sido "borrado del mapa" (2006: 393) por las autoridades franquistas, las apelaciones de la segunda a sus compañeros de destierro para que contaran lo que "nunca contaron los periódicos" (I991: 404) o la exhortación del famoso verso del tercero -"Recuérdalo tú y recuérdalo a los otros" (I982: 372)- así lo confirman. Desde prácticamente la finalización de la guerra, las víctimas exiliadas tuvieron presente la necesidad de rememorar su pasado, y el del legado cultural, político y humano que representaban, para luchar contra la deformación y el ocultamiento al que los poderes franquistas les estaban sometiendo -y, al mismo tiempo, para oponerse a los mensajes triunfalistas con los que en el interior se recordaba a

\footnotetext{
r López de la Vieja ha insistido en cómo la legitimación que otorga a las víctimas su condición tiene también un sentido ético: "La información sobre situaciones densas, moral y políticamente densas, se encuentra bastante limitada por un conjunto de elementos. Resulta especialmente problemático el conocimiento de sucesos trágicos. En tales ocasiones, la literatura cumple una función política y moral, al aportar conocimiento indirecto sobre formas de vida y sobre experiencias límite. (...) El punto de vista individual, las experiencias de los agentes pueden ser más relevantes y enseñar bastante más al lector que el punto de vista universal, en tercera persona" (2003: 34).
} 
quienes habían luchado a favor del Golpe de Estado-. Al suponer "la otredad, la alteridad, el otro [que] contesta y contradice los postulados hegemónicos franquistas" (Martínez, I998: 238), las obras de quienes permanecían en el destierro adquirían un valor de resistencia y contradiscurso. Dado que la Transición no supuso la recuperación plena de sus voces, ni el restablecimiento de un relato histórico que diera cabida a los derrotados, el afán cognitivo de la literatura de la memoria se ha mantenido hasta nuestros días, enlazando así la obra de los exiliados con la de escritores actuales por su lucha contra el olvido que parecía imponerse en la sociedad española².

En una de las novelas de El laberinto mágico de Aub, Campo abierto (I95I), se expone de forma sintomática este carácter cognitivo y memorístico al incluir, en cierto modo de forma similar a la de "Proeza", una larguísima enumeración que desgrana los nombres y algunas breves pinceladas biográficas de quienes conformaron uno de tantos batallones de milicianos que se formaron durante los primeros meses de la guerra3 ${ }^{3}$. Como ha señalado Michael Ugarte, semejante listado, que interrumpe bruscamente y se presenta ajeno a todas las lógicas del ritmo narrativo, es "un arma de la sociedad contra el olvido y la muerte", "una respuesta al Valle de los Caídos" y una forma, en definitiva, de librar la "batalla por recordar" (I999: 132) al rendir homenaje a esos perdedores -de la guerra, pero también de la historia- que jamás aparecieron en ninguno de los monumentos conmemorativos que poblaron España durante la dictadura. De este modo, el pasaje de Aub, como el de Barea y como el de prácticamente toda la literatura que sobre el tema se ha escrito en España desde la óptica de la memoria, se convierte en un gesto de reparación, pues se entiende con él que "el acto de contar las historias de las víctimas olvidadas, devolverles sus historias individuales, recordar sus nombres y reconocer sus

\footnotetext{
${ }^{2}$ Según Paloma Aguilar y Leight A. Payne, durante el periodo reformista que siguió a la muerte de Franco, "se conformó un entorno en el que el olvido deliberado de los acontecimientos más trágicos del pasado bloqueaba cualquier cuestionamiento de un relato basado en la reconciliación nacional y el reparto simétrico de culpas por las barbaridades cometidas", lo que conllevó, en primer lugar, que no se reclamase "ni una verdad oficial, ni reparaciones completas, ni la justicia que exigieron otras transiciones posteriores" y, en segundo lugar, que se fomentase "la decisión de pasar la página del pasado violento", dejando "fuera del relato (...) toda la violencia desatada durante la prolongada dictadura" (2018: 18, 27 y 33).

3 "Juan Pajares, de Argamasilla, veinticuatro años, soltero y de buen ver, moreno con barros; Juan Miguel González, de Madrid, treinta y seis años, casado, con tres hijos, tiene acedías y se las aguanta, enemigo personal que es del bicarbonato; Adrián Costa, de Calaceite, cincuenta años redondos y mal aprovechados, viudo dos veces, con hijos, uno de ellos está ahí: Miguel, oficial en una barbería en la calle de la Montera (...); Santiago Pérez, de Guadalajara, tan chulo como siempre; Fernando Sánchez, de Logroño, con su constipado" (Aub, 200I: 523).
} 
sufrimientos es una forma de (...) compensar las injusticias cometidas" (Lauge Hansen, 20I8). La tesis de que la indagación en el pasado para desvelar las injusticias sufridas por colectivos hasta ahora ignorados implica reconocimiento y justicia ha sido también explicada por Martínez Rubio, para quien buena parte de la literatura española de los siglos xx y xxi se ha caracterizado "por intentar contestar a las preguntas, a los interrogantes y a los vacíos que la Historia en mayúsculas, o la intrahistoria en minúscula, (...) van dejando como un síntoma de insatisfacción y, en consecuencia, como una llamada a la plenitud" (2015: I53).

Se entiende así que la memoria es "una actividad hermenéutica [a través de la que] hacer visible lo invisible” (Mate, 2008: I67), algo que, en mayor o menor medida, está presente en prácticamente todas las definiciones que durante los últimos años se han dado en el campo académico hispánico sobre lo que se ha dado en llamar la "literatura de la memoria". Sin ánimo de exhaustividad, Ignacio Soldevila Durante y Javier Lluch-Prats se han referido a ella incidiendo en su contribución a la "recuperación de pasajes ausentes en el discurso historiográfico hegemónico que ha sido transmitido" (2006: 35); Georges Tyras ha afirmado que su intención es "proyectar luz (...) sobre territorios de la historia poco o parcialmente explotados" (Tyras, 20I3); y Txetxu Aguado la ha calificado como aquella que "quiere descubrir alguna verdad que deliberadamente se ha perdido, alguna voz que se ha querido enterrar para siempre, algún testimonio que no ha encontrado la expresión de su antiguo actuar y pensar" (20I0: I4I). Así, poniendo de manifiesto su interés por superar las consecuencias del control sobre la memoria colectiva que impuso el franquismo durante sus más de tres décadas, las obras literarias que durante las últimas décadas, y fundamentalmente desde el inicio del siglo xxi, se han ocupado de rememorar de forma sistemática, casi obsesiva, lo sucedido en el traumático pasado reciente desde los paradigmas de la posmemoria y la memoria afiliativa ${ }^{4}$ se han centrado en recuperar la memoria y situar en una posición central a todos los colectivos que, de un modo u otro, fueron ultrajados por el franquismo. Las formas a través de las que lo han hecho han sido diversas, y entre ellas se observan como principales tendencias la narración

\footnotetext{
${ }^{4}$ Grosso modo, ambos conceptos se basan en la relación entre los sucesos traumáticos y violentos del pasado y su posterior relato en el presente por parte de quien, pese a no haberlos sufrido directamente, se siente responsable de su narración. En el caso de la posmemoria, la relación entre la víctima y quien narra su experiencia se inscribe en el ámbito familiar (Hirsch, 2008), mientras que en el de la memoria afiliativa los vínculos entre ambos se basan en la identificación política o ideológica (Faber, 20II).
} 
de sucesos ambientados en tiempos pretéritos de la guerra o la dictadura relacionados con la represión; la dimensión metaficcional a través de la que reflexionar sobre los mecanismos manipuladores del relato impuesto desde el poder; y el uso de estructuras de investigación regresivas destinadas a esclarecer desde el presente algún suceso del pasado que represente la capacidad violenta y punitiva del franquismo. De ese modo, se confirma que la taxonomía de "literatura de la memoria" responde, por encima de cuestiones temáticas, formales o argumentales, a cuestiones pragmáticas, pues en ella prima por encima de todo la intención de visibilizar tanto lo que ocurrió como, sobre todo, a quienes les ocurrió.

No obstante, como sucedía en el relato de Barea, ese afán por dar voz y presencia a quien jamás la ha tenido provoca la omisión reiterada del victimario, con lo que se termina por difuminar la responsabilidad individual de los causantes de los actos de violencia represiva que se quieren denunciar. Hay, claro está, una constante crítica hacia el franquismo, pero la ausencia generalizada de personajes protagónicos que lo representen, y la estereotipación con la que en algunos casos han sido descritos -a medio camino entre la crueldad extrema sin matices y la ridiculización grotesca-, provoca que esa denuncia termine frecuentemente por quedarse en banales generalizaciones de trazo grueso que, al no indagar en las acciones de los verdugos, conforman una "memoria que es fetiche antes de que de uso, (...) de tarareo antes de que de conocimiento, (...) de anécdotas antes de que de hechos, palabras, responsabilidades" (Rosa, 2005: 32).

\section{3. “¿Por qué escribimos sobre ellas? Porque no son dignas del anonimato"}

Sin embargo, en los últimos años ha crecido exponencialmente el interés por los verdugos y, de forma especial, por la reflexión sobre su identidad y sobre las razones que motivaron su comportamiento5. Entre la nómina de autores que, desde perspectivas y con enfoques diferentes, se han aproximado a los victimarios están Javier Cercas -que tanto en Soldados de Salamina (200I) como, sobre todo, en El monarca de las sombras (20I7) presenta a personajes afines al bando sublevado como víctimas de las circunstancias históricas y

\footnotetext{
5 Para profundizar en el creciente interés por los victimarios mostrado por la literatura española, véanse los trabajos de Sánchez León (20I8), Lauge Hansen (20I8) y Sánchez Biosca y Ferrer (2019).
} 
del poder corruptor del totalitarismo-; Miguel Dalmau -cuya La noche del Diablo (2009) está narrada por un sacerdote que fue testigo, y en cierto modo cómplice, de las atrocidades que llevó a cabo durante la contienda un grupo de sublevados comandado por un siniestro militar italiano-; Ignacio Martínez de Pisón -que en Dientes de leche (20II) y El día de mañana (20I4) relató respectivamente las historias de un voluntario italiano que luchó en el ejército franquista y de un confidente de la Brigada Político-Social, tratando con ambas, como es habitual en su narrativa, de engarzar su peripecia vital en el marco colectivo de la historia reciente-; Cristina Fallarás -que reflexionó en Honrarás a tu padre y a tu madre (20I8) sobre su propia identidad y sobre la construcción del relato histórico que había ido recibiendo al evocar su memoria familiar, escindida ente la condición de víctima de su abuelo paterno y la de verdugo del materno-; o Alfons Cervera -dos de cuyas últimas novelas, Todo lejos (20I4) y La noche en que los Beatles llegaron a Barcelona (20I7), relatan sendos episodios de torturas y violencia policial en cuya reconstrucción polifónica se da voz a los verdugos, escudados en un discurso que, a medio camino entre la negación, el silencio y la justificación, adquiere un evidente valor simbólico al concluir, en la línea de la ya mencionada tendencia a pasar página y dar por amortizado el pasado que se trató de imponer por algunos sectores en la Transición, que "lo que pasó en aquellos días no interesa a nadie, no sé para qué tanto recordar" (Cervera, 20I4: 44)-.

Para Sánchez León, las razones del creciente interés por los perpetradores, circunscritas en un contexto internacional al que ha llegado a referirse como el "giro hacia el victimario", se deben precisamente a la "saturación del paradigma de la víctima / testigo", así como a la necesidad de "reflexionar ante las motivaciones" (2018: I68-169) que provocaron la aparente irracionalidad de sus comportamientos. Más allá de la mera reiteración con la que se ha puesto el foco sobre estas figuras, para explicar tal saturación, se ha de hacer referencia a los peligros que ya detectó Todorov en privilegiar de forma sistemática el discurso de las víctimas sobre el de los demás ${ }^{6}$, gráficamente expresado en su provocadora afirmación de que "nadie quiere ser una víctima, [pero] todos, en cambio, quieren haberlo sido, sin serlo más, [pues] aspiran al estatuto de

\footnotetext{
${ }^{6}$ Refiriéndose a autores como Ángel Loureiro, Sánchez León ha advertido del surgimiento de "voces críticas que señalan que convertir la memoria en el 'repositorio de la verdad' no hace sino poner sobre la mesa la cuestión de acerca de quién o para quién es dicha verdad” (2018: I75). En el caso español, esa problemática fue gráficamente puesta de manifiesto con el caso de Enric Marco, cuyo discurso falaz sobre su inexistente experiencia en Mauthausen estuvo legitimado, básicamente, por su condición de víctima.
} 
víctima" (2000: 34). Además, en el ámbito literario español, es evidente que su uso recurrente ha puesto de manifiesto el riesgo de fosilizar hasta el punto de convertir en tópico literario a víctimas y testigos, que en algunas ocasiones han pasado a ser simples "pretextos narrativos, (...) [en un] ejercicio de estilo" (Rosa, 2007: 444) que, lejos de reclamar atención sobre su discurso, recurre a ellos como forma de proyectar "una reconstrucción despolitizada y deshistoriorizada de la historia, invitando al lector a mantener una relación complaciente con su pasado" (Becerra, 2015: 36 ).

Frente a esos riesgos, el tratamiento literario del victimario se ha revelado en algunos casos como una forma de explorar nuevas vías a través de las que indagar en la memoria colectiva de la sociedad, puesto que, como ha señalado Lauge Hansen, "la literatura tiene la obligación de abrirnos los ojos para ver cómo se presenta el mundo visto a ojos de las personas en camino de convertirse en victimarios" (20I8). Es decir, escribir sobre los verdugos no ha de interpretarse como una forma de perpetuar la posición de poder que mantuvieron en la configuración de la memoria colectiva durante décadas, sino, más bien, como una forma más de reparación de las víctimas al desarrollar "la función política y social de imaginar los contextos sociales, los procesos políticos y las situaciones existenciales que permiten la deshumanización" (Lauge Hanse, 20I8) a la que fueron sometidas. Así sucede en el caso de Dicen (2019), de Susana Sánchez Arins, que en cierto modo conecta con las intenciones pragmáticas del relato de Barea, del listado de Aub y de toda la literatura de la memoria al partir de la "prevención moral que solo aconseja ahondar en la racionalidad del victimario en la medida que contribuya a dignificar a las víctimas" (Sánchez León, 20I8: I70). Esa intención se explicita en su aparato paratextual, ya que en la dedicatoria se menciona, además de al padre de la autora -víctima indirecta de las atrocidades del personaje principal-, a todos quienes "luchan contra la desmemoria", y se pone de manifiesto a lo largo de la obra, en la que se detallan los nombres de numerosas víctimas de la represión durante la posguerra en la zona de Galicia en la que se ambienta.

Publicada originalmente en gallego con el título de Seique en 2015 y traducida al castellano por la propia autora, la novela se caracteriza por un singular estilo que adopta formas propias de la prosa poética, prescinde por completo de las mayúsculas y se distribuye en capítulos brevísimos -en ocasiones de una sola línea- entre los que no hay ilación argumental ni continuidad temporal. A través de esa estructura fragmentaria que permite ir narrando breves episodios históricos e ir aportando puntuales semblanzas biográficas, se va reconstruyendo la historia de Manuel García Sampayo, el tío abuelo de 
la autora, un falangista "de camisa azul y pistola en el cinto" que, en palabras del historiador gallego Celso Milleiro "es considerado, por los testimonios orales, el más grande represor en las tierras de ribadumia, meis y cambados" (Sánchez Arins, 20I9: I28). Lejos de ser baladí, la alusión a la oralidad de las acusaciones resulta fundamental por dos razones: en primer lugar, por la relevancia que tuvo la transmisión oral en la composición de la obra y en el proceso de documentación que llevó a cabo Sánchez Arins -y de ahí el título de Dicen 7 ; en segundo lugar, por el hecho de que, como se repite varias veces a lo largo de la narración, "dicen que la historia la escriben los vencedores, pero también es cierto que la inescriben" (2019: 39, I24 y I68), de lo que fue consciente la propia autora cuando descubrió, en las pesquisas que realizó en archivos para buscar información sobre su familiar, que llegó a ser alcalde a comienzos de la década de I940 y de quien por tanto algún rastro documental tenía que haber, que "la verdad no sale al encuentro en los fondos archivísticos" y que "los fondos de la falange están higienizados, depurados, trasquilados, purgados, mondos y lirondos. quien no quiso figurar en ellos tuvo tiempo de borrar sus huellas" (2019: I32-I33). Ante semejante panorama, el testimonio oral de las víctimas se revela fundamental, pues se convierte en el único modo de luchar contra el manto de silencio y olvido con el que los perpetradores quisieron tapar sus actos. Por eso escribir sobre un verdugo como el tío Manuel se convierte en un acto de memoria de dimensiones análogas al que supone escribir sobre las víctimas a las que reprimió desde la posición de poder que mantuvo desde el triunfo de la sublevación militar en Galicia al comienzo de la Guerra Civil:

las vidas son vidas cuando son nombradas y habladas y dichas. (...) ahí reside la importancia de la memoria. en dar espacio a los nombres y a los hechos.

(...) hay personas que se empeñan en no haber sido, en no haber existido, en no haber vivido. muere quien podía hablar de ellas, quien podía contar sus vidas y hechos. y rastreamos archivos y bibliotecas, mostradores de notarías, cajones con viejas cartas, hemerotecas de periódicos que en un tiempo fueron,

\footnotetext{
7 La significación polisémica y simbólica del título ha sido explicada por Alfons Cervera: “Tiene Dicen esa posibilidad de quien lee el libro como si las palabras se clavan en la realidad (o en la verdad, por más poliédrica que esta sea) o echan a volar sin afirmarse en la rama del árbol de la memoria. O lo contrario en otra posibilidad a la hora de entender el título: afirmándose en la rama inhóspita de entender el título como algo que se presenta como una habladuría, como dejando a la decisión de ese árbol, dejando bien claro que lo que se cuenta pasó así, digan lo que digan los más tarde emboscados artificieros del horror" (2019).
} 
rumores al aire de tabernas y no damos con esa gente. no quisieron tener memoria.

entonces, ¿por qué escribimos sobre ellas? porque sus vidas no son dignas del anonimato. porque sí vivieron sus vidas y otras gentes las padecieron. porque causaron dolor y terror, miedo y muerte.

porque fueron malas. y poderosas (20I9: 2I).

Para Sánchez Arins, el imperativo moral no implica solo la reivindicación de la memoria de las víctimas, sino también la de sus verdugos. De ahí que en Dicen se narren historias acaecidas durante la guerra o en la inmediata posguerra como la de Castor Codal, a quien se vio por última vez "apalizado y completamente desnudo, (...) amarrado a una escalera de mano para enterrarlo" (20I9: I66); la de Manuela Abal, a quien "le pusieron una cuerda en el cuello y tiraron de ella como de una vaca abierta" (2019: I64); la de Gerardo y Paulino, que murieron "molidos a palos", "carcomidos por las balas", y a los que "de tan quebrantados que estaban, la familia solo pudo reconocer los dientes de oro" (20I9: I48); o la de Ramón Barreiro, un joven de diecinueve años al que después de matar le cortaron "un dedo para apropiarse del anillo" a cuyo padre "de la paliza que le dieron, quedó lisiado para siempre" y a cuya madre "la raparon al cero (...), la violaron, no sin antes llamarla puta (...) y la cegaron con ácido" (2019: IGI-I63). Junto a sus dramáticas peripecias, y a otras muchas que aparecen en las páginas de la obra, se van conformando una retahíla de nombres que, al igual que el listado de Max Aub, permite que su recuerdo no caiga en el olvido pero que, a diferencia de casi toda la literatura que se ha ocupado del pasado traumático español, también fija su atención en los responsables de su tormento. De hecho, por encima de todas las historias que se relatan se alza la del tío Manuel, erigido en gran protagonista pese a que, como reconoce la autora, su nombre "no aparece en causas, denuncias o declaraciones" y “a la pregunta de si (...) participó en alguna paliza, alguna tortura, la respuesta [de la historiografía y la documentación] es el silencio" (2019: I28).

Para dar respuesta a las interrogaciones que la investigación archivística no pudo resolver, y teniendo en cuenta que la propia Sánchez Arins ha reconocido que "no quería inventar, no quería cubrir los espacios en blanco sobre la Guerra Civil” (Consteila, 20I9) a través de la ficción, los testimonios orales de quienes conocieron al protagonista se convierten en fundamentales. Y, entre ellos, cobran especial relevancia, como no podía ser de otro modo en una obra inscrita en el ámbito de la memoria familiar, los de sus propios parientes, especialmente los de los tíos abuelos de la autora, hermanos del 
tío Manuel. La importancia de la voz de los familiares no solo reside en la legitimidad que les otorga el hecho de haber conocido de primera mano al personaje, y saber de algunas de sus fechorías, sino también y sobre todo en su condición de víctimas que fueron humilladas, robadas y perseguidas por alguien con quienes compartían apellido y consanguinidad. No en vano, otra de las frases que se repite como si fuera una letanía en numerosas ocasiones a lo largo de la narración hasta convertirse casi en su leitmotiv es "si fue así de malo con su familia, como sería con los de fuera...”. Aunque los puntos suspensivos inciden, al igual que el título de la obra, en la imposibilidad de certificar la verdadera responsabilidad del tío Manuel en todos los actos de barbarie que aparecen en el libro, la frase expone de forma paradigmática la naturaleza monstruosa del personaje y, al mismo tiempo y gracias a su estructura condicional, parece disipar las dudas sobre la posibilidad de que alguien incapaz de no sentir las más mínima piedad por sus familiares se convierta en un asesino y un torturador.

A través de las historias que la autora fue conociendo en el ámbito familiar, gracias fundamentalmente a sus tías abuelas -lo que dota al relato de un doble valor de contradiscurso, puesto que no solo otorga la voz a las víctimas, sino también a las mujeres-, Dicen va dando cuenta del maltrato que Manuel fue infringiendo a sus parientes. De esa forma, la dimensión de posmemoria de la obra adquiere un sentido dual, y en cierto modo paradójico, puesto que si por un lado hace suyo el discurso de los parientes que fueron ultrajados y merecen el reconocimiento que nunca tuvieron, por otro denuncia y repudia al también familiar que los llevó a cabo. De entre todas las vejaciones que se desglosan, probablemente ninguna sea tan simbólica como la que se evoca al recordar la humillación que sufrió el bisabuelo de Sánchez Arins, padre del protagonista, "con el yugo de los bueyes al cuello, tirando del arado (...) gradando sus propias tierras con sus propios aperos y su poca fuerza" (20I9) 32). La violencia ejercida no se limitó a las palizas, pues conllevó también el engaño para manipular documentos y quedarse con toda la herencia familiar, la delación que provocó el encarcelamiento o la huida al exilio de algunos de sus hermanos y, en definitiva, la ruptura de un sólido núcleo afectivo que se vio abocado a la progresiva disgregación tras la Guerra Civil -lo que lleva a la autora a lamentarse de proceder "de una familia edificada en morriñas, en nostalgias de tiempos pasados (...), en rabia” (2019: I0)-.

De hecho, la propia Sánchez Arins llegó a señalar en una entrevista que, durante el franquismo, en muchas ocasiones "el primer control represivo venía en aquellos años del cabeza de familia, del padre, del hermano mayor o 
del marido" (Losa, 20I9), confirmando que, como ejemplifica su obra, es imposible deslindar la estructura de dominación que el franquismo instauró en la esfera pública de la que el patriarcado impuso en muchos hogares. De ahí que resulte sumamente interesante comprobar cómo en la configuración de ese personaje malévolo que fue el tío Manuel, en lugar de recurrir a la tópica descripción demoníaca irracional o a la "banalidad del mal" con la que tan frecuentemente se ha identificado el comportamiento de los verdugos en contextos totalitarios, se funden lo personal y lo social al mostrar cómo la guerra y la dictadura permitieron que tipos como él actuaran desde la más absoluta impunidad:

a veces preferimos creer en la locura o en la ruindad de una persona, de un hitler, de un videla, de un salazar, para conseguir acoger en nuestras entrañas las atrocidades de las que somos víctimas o testigos. otras veces pensamos que es la disposición del sistema social o político, autoritaria, militarizada, patriarcalizada, la que nos agrade de manera perversamente organizada.

en realidad, ambas se complementan. un sistema pernicioso hace emerger de las simas de la tierra a la ruindad de aquellas personas dispuestas a vivir indignas. no hay violencia sin agresor deshumanizado (2019: 6I).

La incardinación de la actuación del tío Manuel en el sistema represor franquista se manifiesta en su condición de representante del régimen como falangista que llegó a ocupar una alcaldía y miembro de una de las cuadrillas que instauraron el terror a través de "paseos" y palizas durante la guerra y la primera posguerra -cuya absoluta falta de humanidad queda subrayada al señalar que uno de sus integrantes "llevaba anotado el número de víctimas en la chapa del cinturón” (20I9: I2I)-. Además, también se evidencia con la reproducción en la obra de las palabras con las que el general Mola animó a sus correligionarios durante la contienda a "sembrar el terror como grano de maíz" para "dejar la sensación de dominio eliminando sin inquietud de consciencia ni dudosa vacilación a todas aquellas personas que no piensen del mismo modo que nosotros" (2019: 65). Las palizas y los asesinatos de los que "dicen" que fue responsable el protagonista se inscriben así en el sistemático plan de dominación ideado por los rebeldes, por mucho que sus causas inmediatas fueran en muchos casos el ajuste de cuentas personal, las viejas rencillas o la mera avaricia. Al relatar una de las primeras batidas en las que participó, al poco tiempo de iniciarse la guerra -que en Galicia apenas conllevó combates, al triunfar desde prácticamente el comienzo la sublevación, pero sí un largo periodo de represión-, y que conllevó el asesinato de cinco 
republicanos que permanecían huidos en el monte, Sánchez Arins termina reconociendo no poder creer "que el tío manuel no disfrutara con esta partida. con el as a cinto" (2019: I40), demostrando con ello que toda la maldad que pudiera haber en él-recuérdese la insistente letanía de "si fue malo con...", así como las frases en que sus familiares decían que "nunca fue bueno" (2019: I68)- encontró en la contienda y en el régimen que trajo consigo el contexto ideal para desarrollarla.

\section{4. "No decir las cosas era la mejor manera de borrarlas"}

A través del microcosmos de la familia de la autora, convertida en epítome de la sociedad española, Dicen pone de manifiesto las diferentes formas de afrontar el recuerdo del pasado. No es anecdótico, por tanto, que Sánchez Arins rememore cómo, frente a la actitud de algunas de sus tías, su abuela, también hermana del tío Manuel, jamás relatase las barbaridades a las que este había sometido a sus familiares y vecinos. Su postura ejemplifica esa idea que sostiene que "no decir las cosas era la mejor manera de borrarlas, de hacer desaparecer unos hechos que, de solo pensarlos, la horrorizaban" (2019: 39). Aunque este caso concreto se deba al miedo y a la vergüenza -y quizá también a la costumbre-, esa actitud surgió en muchas ocasiones de la complicidad y de la convicción de que la perpetuación del silencio terminaría por borrar las huellas de lo que sucedió. Podrían quedar rastros de las víctimas, pero parece que no estarían completos si no se ponen en relación con los de quienes las convirtieron en tales. Por eso escribir sobre los verdugos también puede ser, además de una forma de oponerse desde la literatura a su intento de quedar impunes, un modo de iluminar a las víctimas, como demuestra Dicen al reivindicar la memoria de los ultrajados, los perseguidos, los robados y los asesinados por el franquismo desvelando la identidad del perpetrador que se cebó con ellos, y al intentar explicar cómo fue posible que llevase a cabo de forma tan impune como abusiva semejantes actos de iniquidad. Enlazando con una dimensión memorística que, lejos de ser exclusivamente contemporánea, hunde sus raíces en la literatura republicana que se escribió durante la propia Guerra Civil y desde el exilio, la obra de Susana Sánchez Arins confirma que la reparación de la memoria de las víctimas y el conocimiento de lo que les sucedió también es posible a partir del desvelamiento de sus verdugos. O, lo que es lo mismo: que los asesinos, a diferencia de lo que sostenía el relato de Barea, sí tienen nombre, y es necesario recordarlo también. 


\section{Bibliografía}

Aguado, Txetxu. 2010. Tiempo de ausencias y vacíos. Escrituras de memoria e identidad. Bilbao: Deusto Publicaciones.

Aguilar Fernández, Paloma \& Payne, Leigh A. 2018. El resurgir del pasado en España. Fosas de víctimas y confesiones de verdugos. Madrid: Taurus.

Aub, Max. 200I. Obras completas Vol. II. Valencia: Generalitat Valenciana, Diputació de Valencia.

Barea, Arturo. 20I9. Cuentos completos. Madrid: DeBolsillo.

Becerra, David. 20I5. La Guerra Civil como moda literaria. Madrid: Clave intelectual.

Benjamin, Walter. 2008. Sobre el concepto de historia. En Obras, libro I, volumen 2. Madrid: Abada, 303-318.

Cernuda, Luis. I982. La realidad y el deseo. México D. F.: Fondo de Cultura Económica. Cervera, Alfons. 20I4. Todo lejos. Barcelona: Piel de Zapa.

Cervera, Alfons. 20I9. Dicen: El árbol de la memoria. Infolibre, 3 de mayo de 2019. https://www.infolibre.es/noticias/los_diablos_azules/2019/05/03/el_arbol_ memoria_94524_I82I.html

Consteila, Tereixa. 20I9. La maldad no tiene derecho al anonimato. El País, 28 de abril de 20I9. https://elpais.com/cultura/20I9/04/27/actualidad/ I556374419_848539.html

Faber, Sebastiaan. 20Iı. La literatura como acto filiativo: la nueva novela de la Guerra Civil (2000-2007). En Álvarez Blanco, Palmar \& Dorca, Toni (eds.) Contornos de la narrativa española actual (2000-2010): un diálogo entre creadores y críticos. Madrid/Frankfurt: Iberoamericana/Vervuet, ıoI-Iıo.

Hirsch, Marianne. 2008. The Generation of Postmemory. Poetics Today 29: I03-I28.

Lauge Hanse, Hans. 2018. Víctimas y victimarios: Trauma social y representación de víctimas y victimarios en la novela española de memoria. Passés Futurs 3. https://www.politika.io/fr/notice/victimas-y-victimarios-trauma-social-y -representacion-victimas-y-victimarios-novela-espanola

León, M. ${ }^{a}$ Teresa. I991. Memoria de la melancolía. Madrid: Castalia.

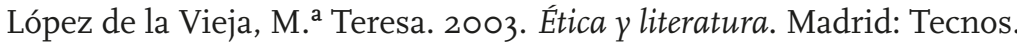

Losa, Juan. 20i9. Memoria histórica: Cuando el asesino falangista es de la familia. Público, 22 de abril de 20I9. https://www.publico.es/culturas/memoria-historica-dicen.html

Martínez, Josebe, I998. Hegemonía intelectual, exilio y continuidad histórica. En Aznar Soler, Manuel (ed.) El exilio literario español de 1939: actas del Primer Congreso Internacional. Bellaterrra: Gexel, 325-333.

Martínez Rubio, José. 20I5. Las formas de la verdad. Investigación, docuficción y memoria en la novela hispánica. Barcelona: Anthropos.

Mate, Reyes. 2008. La herencia del olvido. Madrid: Errata Naturae.

Rosa, Isaac. 2005. El vano ayer. Barcelona: Seix Barral.

Rosa, Isaac. 2007. ¡Otra maldita novela sobre la Guerra Civil! Barcelona: Seix Barral.

Sánchez Arins, Susana. 2019. Dicen. Madrid: De Conatus. 
Sánchez Biosca, Vicente \& Ferrar, Anacleto. 2019. El infierno del perpetrador: imágenes, relatos y conceptos. Barcelona: Bellaterra.

Sánchez León, Pablo. 20ı8. “Esa tranquilidad terrible”. La identidad del perpetrador en el "giro" victimario. Memoria y Narración. Revista de estudios sobre el pasado conflictivo de sociedades $y$ culturas contemporáneas I: I67-I83. doi: https://doi. org/I0.56I7/myn.5484.

Soldevila Durante, Ignacio \& Lluch-Prats, Javier. 2006. Novela histórica y responsabilidad social del escritor: el camino trazado por Benjamín Prado en Mala gente que camina. Olivar 8: 33-44.

Todorov, Tzvetan. 2000. Los abusos de la memoria. Barcelona: Paidós.

Tyras, Georges. 2013. Alfons Cervera: hacia una poética de las voces. En Cervera, Alfons Las voces fugitivas. Barcelona: Piel de Zapa, I3-20.

Ugarte, Michael. I999. Literatura española en el exilio. Un estudio comparativo. Madrid: Siglo XXI.

Vinyes, Ricard. 20ıо. La reconciliación como ideología. El País, i2 de agosto de 20 o.

Wieviorka, Annette. 2006. The Era of Witness. Ithaca: Cornell University Press. 
